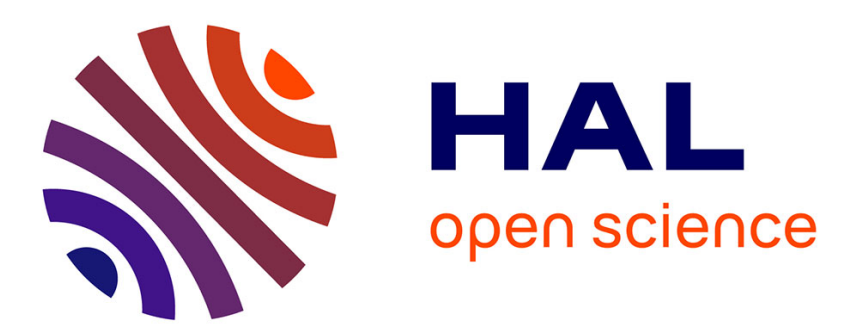

\title{
The normalization of online campaigning in the web.2.0 era
}

Karolina Koc-Michalska, Darren G. Lilleker, Alison Smith, Daniel Weissmann

\section{To cite this version:}

Karolina Koc-Michalska, Darren G. Lilleker, Alison Smith, Daniel Weissmann. The normalization of online campaigning in the web.2.0 era. European Journal of Communication, 2016, 10.1177/0267323116647236 . hal-01316460

\section{HAL Id: hal-01316460 \\ https://hal-audencia.archives-ouvertes.fr/hal-01316460}

Submitted on 20 May 2016

HAL is a multi-disciplinary open access archive for the deposit and dissemination of scientific research documents, whether they are published or not. The documents may come from teaching and research institutions in France or abroad, or from public or private research centers.
L'archive ouverte pluridisciplinaire HAL, est destinée au dépôt et à la diffusion de documents scientifiques de niveau recherche, publiés ou non, émanant des établissements d'enseignement et de recherche français ou étrangers, des laboratoires publics ou privés. 
The normalization of online campaigning in the web.2.0 era $^{1}$

Karolina Koc-Michalska

Assistant Professor at Audencia Business School, Nantes, France

Associated researcher at CEVIPOF, Sciences-Po Paris, France

kkocmichalska@audencia.com

Darren G. Lilleker

Associate Professor of Political Communication

Bournemouth University

dlilleker@bournemouth.ac.uk

Alison Smith

Student Politics and Media programme in the Faculty of Media and Communication, Bournemouth University, Head of communications for the Jurassica project

alison@jurassica.org

Daniel Weissmann

Student Politics and Media programme in the Faculty of Media and Communication, Bournemouth University daniel.weissmann@hotmail.com

\begin{abstract}
This paper is based on a comparative study of online campaigning and its effects by country and over time, using four of the largest EU member states (France, Germany, Poland and UK) as a case study. Our research explores the extent of embeddedness of online campaigning, the strategic uses of the whole online environment, and in particular the use of the interactive features associated with web.2.0 era. However. our research goes beyond studies of online campaigning as we also determine whether online campaigning as we also determine whether online campaigning performance across platforms matters in electoral terms. Our data supports the normalization hypothesis which shows overall low levels of innovation but that the parties with the highest resources tend to develop online campaigns with the highest functionality. We find that there is a vote dividend for those parties which utilized web.2.0 features the most and so offered visitors to their web presence a more interactive experience.
\end{abstract}

\title{
Introduction
}

The $21^{\text {st }}$ Century cluttered and fragmented media environment means political campaigns find audiences hard to reach. Face-to-face communication remains the top communication priority (Lilleker, Stetka \& Tenscher, 2014) but reaching voters on doorsteps and high streets is highly challenging in an era of hectic social lives, irregular work patterns and multi-occupancy accommodation. To compensate for communication challenges, and due to the potential reach and low resource cost, campaigning using a range of digital tools and platforms is now firmly embedded within party campaign strategies with usage of a range of online tools, from email and websites (which have a long history) to the more recently popular social tools

\footnotetext{
${ }^{1}$ Paper is continuation of the CENMEP 2009 project. The collection of the data from 2014 election was in part financially supported by Foundation Audencia Business School research grant.
} 
(Facebook, Twitter, YouTube) now almost de rigueur (Lilleker, Stetka \& Tenscher, 2014). Studies of online campaigning find that election campaigns utilise the online environment mainly for providing information (persuading) as well as making attempts to mobilise party members and supporters. Despite the interactive affordances of digital technologies, hosting debates or discussions around party policy, campaigns and tactics have historically been marginal activities. Our data explores whether the limited functional use of the online environment remains the case through a case study of four nations: France, Germany, Poland and the UK. Our sample represent the largest EU nations, all with a regional list system except Poland which has regional lists but uses a preferential voting system, but differing party systems and contexts (see also Lilleker, Koc-Michalska et al., 2011). In order to assess the evolution of online campaigning strategy we compare data from the 2009 and 2014 European Parliamentary elections. However, this study goes beyond studies of online campaigning by developing analytical tools to determine whether online campaigning performance across platforms matters in electoral terms. We hypothesise that greater use of specific digital platforms for certain functions, in particular greater interactive use of social media, may have a positive impact on vote share. We therefore determine patterns in party strategies, detect change over time and testing the explanatory power of the normalization and equalization hypotheses for explaining online campaign performance. We also use the data to explore the extent that online campaign performance, and the adoption of interactive functions, impact upon party vote shares to determine whether online campaigning might have an impact upon election outcomes.

\section{Theoretical framework}

New communication technologies, it was initially suggested, would have a profound impact on existing power relationships within society, in particular leading to a flatter, more equal hierarchy between organisations and ideologies. The so-called cyber-optimists suggested that greater use of the Internet by individual citizens would 'level the playing field' (Bimber, 1998; Rheingold, 1993). The equalization hypothesis argued that existing power elites' dominance relied upon their greater access to traditional media through the exercise of information subsidies (Gandy et al, 1992). In contrast, in the age of the Internet, communication technologies facilitated the bypassing of traditional media by political actors allowing them to communicate directly to, and in the web.2.0 era, with citizens. Within the context of election contests the equalization hypothesis implied smaller political parties would be more likely to utilise the Internet, and use a range of resources to build awareness and gain support. Early studies within the post-2005 web.2.0 era suggested in particular it would be smaller parties that were most likely to adopt a more interactive paradigm of campaigning to compensate for the low attention mass media would award them (Chen, 2010; Jackson and Lilleker, 2009).

However, empirical evidence largely disproved the equalization hypothesis; rather, in most cases, the normalization of power relations was found in online environments. Empirical findings popularized the normalization hypothesis, which suggests that power relationships are immutable independent of the media environment (Bellamy and Raab, 1999), and therefore political power relations online would demonstrate 'politics as usual' (Margolis and Resnick, 2000). Existing electoral inequalities would be reinforced by digital technologies (D’Alessio, 1997; Davis, 1999) and, independent of the ability to communicate, communicating would not equate to being heard (Hindman, 2008). Put simply the attention which highly resourced political parties are paid offline by traditional media would be the major driver of traffic to their online presences. Similarly, the access to greater resources will mean that the most popular parties in parliament will also be most innovative in their use of digital technology.

The weight of evidence has consistently demonstrated the explanatory power of normalization. Research into online campaigning in Germany during both national (Schweitzer, 2008) and EP elections (Schweitzer, 2009) demonstrated huge disparities between the sophistication of the websites of parliamentary and non- 
parliamentary parties. A similar pattern was demonstrated in a comparative study of the online campaigns of major and minor candidates during the 2007 French presidential elections (Vedel and Koc-Michalska, 2009; Koc-Michalska et al, 2014) and subsequently when comparing Polish and French parties (Koc-Michalska \& Lilleker, 2014). Studies of UK parties found, during election campaigns in the late 1990s, some evidence that smaller parties were the most likely to be early adopters of technology (Gibson and Ward, 1999), specifically those on the right of the political spectrum (Copsey, 2003). However, longitudinal studies have largely found that developments are better explained by the ebb and flow thesis. Ebb and flow recognises that at certain times, some parties will be the most innovative in campaigning. However, any innovation that is seen to have impact is quickly adopted by other parties who may add a further layer of innovation. At the same time studies find early adopters' campaigns become static and less innovative between contests.

Initially this was demonstrated during the UK EP contest in 1999 when smaller parties offered websites with greater functionality than those of larger parties (Gibson and Ward, 2000); equally during the 2005 General Election smaller parties were most likely to use the Internet for mobilizing supporters (Jackson, 2006) and were found to be more likely to explore the potential of web.2.0 applications (Jackson and Lilleker, 2009). However, temporally comparative research allowed the ebb and flow to be visible across elections culminating in the finding that by the 2014 EP election the design and sophistication of the six UK party web presences included in the study was almost identical (Lilleker et al, 2015). While a limited sample the study shows that innovations do not appear to be the result of resources but more likely to be a feature of prevailing thinking within a party as strategy is developed for the context of a specific contest building on lessons from previous performance.

Despite the power of the ebb and flow thesis, normalization remains dominant when looking across the range of studies. Therefore, we would expect that parties with higher levels of representation in national parliaments, so reflecting their support within their nation, and who have long-term experience of competing nationally and in EP contests, would offer the most innovative and sophisticated web presences. In other words the parties with the greatest resources will be most likely to be early adopters of features, and have web presences that encompass a greater number of features and so will have greater functionality. However, given the longitudinal component to our study, it is likely that some evidence will support an 'ebb and flow' of adoption of specific online features and functions, in particular the features which offer interactive functionality to visitors. A previous study of online campaigning across these four nations found "a range of party web presences offering a rich experience that combines engaging features with the delivery of information", however differences could be clearly explained by resources and campaigning experience resulting in the conclusion that "while we find Web 2.0 features to be taken up by all parties across our four nations at the $2009 \mathrm{EP}$ elections, the degree to which this has happened is still a function of traditional patterns in offline politics" (Lilleker et al, 2011: 208). The question this paper poses is whether we find similar results, and so our conclusions present the definitive answer to questions on online campaigning or whether we find evidence of ebb and flow between 2009 and 2014 across time and nations. Arguably, we might expect this to be the case given that a study of the attitudes of campaign managers and strategists in sixteen EU member states showed new media to be fully embedded within campaign design by most parties in most nations. Differences in priorities cannot be explained by national or party-related factors rather, the authors suggest, the extent of new media usage may be more a factor of individual choice among party strategists than the available resources. "Strategists evaluate highly the communication tools they find to be appropriate within the context in which they operate and hence the weightings they award to these tools are shaped by a range of factors" (Lilleker, Tenscher \& Stetka, 2014: 16).

The factor that may determine uptake, or not, of the various functions afforded through the adoption of online communication tools is therefore a judgement regarding the perceived value. Put simply: is there a potential for building a sophisticated website, becoming more interactive, colonising social media and 
building an online network to translate into votes? It has been tentatively argued that this might be the case. Normatively it is suggested that a more interactive and accessible style may be rewarded (Simmons et al, 2010). The challenge, however, is that it is almost impossible to prove unequivocally due to the complexity of isolating any single aspect of a campaign. However, within the context of an EP election, campaigns in these countries tend to be homogenous, they are largely low-resourced, national-level, party-driven campaigns with minimal local campaigning beyond posters and mailouts with media attention being given to the most popular parties. Therefore, within this context we argue that it is possible to assume that all other elements campaign are roughly similar and, using the ceteris paribus principle, consider all other aspects fairly equal so allowing us to detect an effect from web based campaign performance. Due to the number of parties (228) across the four nations there is sufficient number to perform regression analysis; therefore we test whether there are any differentials in vote share which can be explained by online performance scores for the use of features consistent with the information age of Internet communication (web.1.0) or those developed for the interactive age (web.2.0). In particular we are able to determine whether parties who adopt a more interactive communication strategy online gain a vote dividend as some studies have indicated may be the case (Simmons et al, 2010; Koc-Michalska et al, 2014).

This paper therefore focuses on four discrete research questions:

RQ1: Can we detect greater innovations in online campaigning across the EU nations in 2014 as compared to 2009 ?

RQ2: Can we detect a shift to an online communication strategy consistent with the usage of web.2.0 tools in 2014 and are party and nation variables moderating factors?

RQ3: Does the normalization hypothesis remain the most powerful explanatory factor for variation in innovations in the development of online strategies?

RQ4: Can we detect a positive impact from variations in online campaigning styles and strategies on share of vote earned by parties?

\section{Methodology}

Four nations were selected for inclusion in the study: France, Germany, Great Britain and Poland. These represent the largest EU member nations, with the highest number of parties standing for election. These nations elect MEPs from party lists to represent regions within the nation, thus allowing us to isolate national and party-related causes for variances in online communication strategy.

Content analysis of the main party websites, or where appropriate specific campaign websites, was conducted in the last seven days of the campaign (1st -7th June 2009 and 18th - 25th May 2014). The coding scheme was based upon that developed by Gibson and Ward (2000) and updated to include social media in more recent studies (Lilleker \& Jackson, 2009; Koc-Michalska et al, 2014). 214 features, dependent on the type of site, were identified as present or absent using a standardized survey for all countries. The coding was performed on 228 parties (98 in 2009 and 130 in 2014). The number of parties per country, and other key data on the nation is included in Table 1. The parties' selection was according to official registration with national election committees, regardless of results in previous elections. The websites were coded by four coders, all coders passed inter-coder reliability tests (Krippendorff's Alpha (.76)), any irregularities were checked and corrected. The final Holsti reliability coefficient was (.87). This measurement is appropriate for data on a nominal level where coders decide only for absence or presence of features as in our study (cf. Stempel, 2003: 216; Watt and Van den Berg, 1995: 375). 
Table 1 about here please

Features were grouped, first, as belonging to web.1.0 or web.2.0; and also whether the main function was to provide information, encourage visitor engagement, mobilize support or allow interactivity; the groupings are outlined below and full details can be found in Appendix A1. The feature groupings were based upon previous coding schemas developed for the analysis of party websites (de Landtsheer et al., 2005; Gibson and Ward, 2000; Lilleker and Malagon, 2010; Lilleker et al, 2011; Koc-Michalska et al, 2014). Consistent with the approach of Farmer and Fender (2005: 49; see also Lilleker \& Koc-Michalska, 2013; KocMichalska et al, 2014) indexes of the average number of features for each grouping were created: web.1.0, web.2.0, information provision, engagement, mobilization and interactivity. The feature groupings allow us to understand the key functions of parties' websites. To compare online performance we generated an average online performance score (AOP - calculating an overall mean per type of communication from the maximum possible score in that strategy). This allows for straightforward comparisons of categories containing unequal numbers of features (scores are calculated by dividing the number of indicators present by the total number of features within that grouping).

\section{Dependent and independent variables}

The paper is based on seven dependant variables. Six derived from the website content analysis, they are constructed as indexes (see Appendix Table A1).

The two discrete categories, web.1.0 and web.2.0, are constructed from an exclusive set of features (only in one of the categories); and four inclusive indexes (features may belong to more than one index) Information provision, Engagement, Mobilization and Interactivity provision (Lilleker et al 2011). The features used in this paper were available for the construction of the website or social media presence in both years (2009 and 2014) allowing to control for real change in online campaigning and not simply detecting technological development.

Finally, in order to indicate the potential influence of online performance, parties' electoral performance from 2009 and 2014 EP elections is used.

Web.1.0 strategy index is based on the traditional website style and does not employ any interactive feature, it contains 30 features (Cronbach $\alpha=.753$ ). On the contrary web.2.0 is more innovative utilising interactive and discussion based communication and is based on 18 features $(\alpha=.753)$. Those two indexes are further used as independent variables to explain vote share. The correlation between the indexes is (Pearson's $\mathrm{p}=.55)$.

Information provision consists of 22 features $(\alpha=.671)$, Engagement 17 features $(\alpha=.663)$, Mobilization 15 features $(\alpha=.689)$ and Interactivity strategy 15 features $(\alpha=.680)$. As could be expected due to inclusivity of the features the correlations between different indexes is high $(.67<\mathrm{p}>.84)$.

Independent variables follow the literature (Gibson \& Roemelle, 2009; Tenscher \& Mykkänen, 2014; Lilleker et al, 2014) explaining the professionalization of campaigning and parties' electoral outcomes.

Country differences: we control for the difference between countries by including a dummy variable for each country, with Germany as the comparative category. On the four countries' level of comparison this strategy seems to mirror best all the possible meta characteristics (GDP, population size, internet penetration rate etc.).

Time difference, dummy, controls for the election year $(2014=1)$. 
Party characteristics: Parties present in both elections '09/'14 (dummy) controls for parties fielding candidates in both years, 56 parties appear in this group; Party years of existence (continuous) records number of years creation; Party size (dummy) categorizes the parties according to their result in the last national elections and number of seats in the national parliament ${ }^{2}$ (or Vote share in last national election as continuous): major parliamentary (scored above $20 \%{ }^{3}$ in elections and have more than $100 \mathrm{MP}, \mathrm{N}=16$ ), minor parliamentary (other parties present in parliament, $\mathrm{N}=33$ ), major fringe parties (gained more than $1 \%$ of national votes ${ }^{4}, \mathrm{~N}=18$ ), minor fringe parties (all other parties, $\mathrm{N}=161$ ); Number of seats in EP in previous term (continuous) number of seats gained by parties in European Parliament in 2004 and 2009 elections.

Party ideology (dummy) and EU positioning (dummy) variables are based on the data delivered by $E U$ profiler study. $y^{5}$. Party ideology consists of four categories: Right leaning parties ( $\left.\mathrm{N}=58\right)$, Left leaning parties $(\mathrm{N}=92)$, Centre leaning parties ( $\mathrm{N}=26)$ and Single issue/other parties $(\mathrm{N}=52)$. EU positioning identifies three groups: Pro-EU ( $\mathrm{N}=113$, comparative category), Neutral $(\mathrm{N}=59)$ and EU-sceptics $(\mathrm{N}=56)$.

\section{Findings}

\section{Comparisons by nation and party type over time}

The first layer of analysis focuses on comparing the average online performance (AOP) of parties within each nation, by type of party, between the two elections. The simple feature counts shows two clear findings. Firstly France, Germany and Poland show a fairly consistent pattern across contests, with a strong overall AOP for major parties and normalization appears the dominant explanation of differences. Using party support (as determined by their position vis-à-vis the national parliament) we find that the major parties which are likely to have the greatest resources at their disposal also have the most sophisticated online campaigns. Great Britain shows a lower overall AOP, and lower differences for party type, with the peak of innovation for major fringe parties witnessed in 2009. But for all four nations we can observe a smooth transition from major parties downwards in terms of their sophistication in their approach to online campaigning, although this pattern is least pronounced for parties in Great Britain.

The second finding is one of mixed innovations in online campaigning between the nations. The data shows a very clear increase in the use of features between the 2009 and 2014 campaigns by parties in France and Poland, with the latter contest showing significant sophistication of online campaigning (general performance AOP score: FR (2009: .292; 2014: .371; Difference = 79) PL (2009: .246, 2014: .356, Difference $=110$ ). German and Great British parties also show an increase, but this is very small suggesting that their party online strategies were almost identical in both years (general performance AOP score: DE (2009: .291; 2014: .306, Difference = 15) GB (2009: .283, 2014: .300, Difference $=17)$.

When it comes to performance according to party size the picture is similar for France and Great Britain where the performance is standardized, especially in the 2014 context. In Great Britain there is very little difference between the highest and lowest AOP by party type and major and minor parliamentary parties are equal. In France the gradient is fairly shallow from major parliamentary parties through to major fringe parties, normalization is only pronounced in the gap to minor fringe parties. However, with the very

\footnotetext{
${ }^{2}$ We used a mixed system in order to detect parties which gained few votes in elections, however due to electoral systems that have representatives in the national parliament (for example in France Debout la République gained .56\% of votes in 2012 legislative elections but due to coalition electoral system has two representatives in the Assemblée nationale http://www.france-politique.fr/elections-legislatives-2012.htm (accessed 05.01.2015)

${ }^{3}$ With the exception of Liberal Democrats (UK) who gained $22 \%$ of votes however are in the minor parliamentary group

${ }^{4}$ With some exceptions, please see the footnote above

${ }^{5}$ EU profiler study directed by Alexander Trechsel and his team at EUI University, Florence. (Garzia et al, 2015)
} 
pronounced differences between party types in German and Poland we suggest that differences in the sophistication of online campaigns are largely explained by the normalization thesis. The only clear exception to this pattern can be found in Great Britain in 2009 where the minor parliamentary parties outperformed major parliamentary parties, and the major fringe parties outperformed both of them. In 2014 overall online performance shows less differences between parties with vastly different resources leading the online campaign to appear more equal, if relatively less innovative. This may be due partially to the promotion of UKIP to being a minor parliamentary party (having gained two seats in by-elections in 2014), in 2009 it was a minor party. There is also one departure from the normalisation pattern, in 2009, in France, where minor fringe parties outperformed major fringe parties. The fact that those anomalies are no longer visible in 2014 appears to confirm that with time the explanatory power of the normalization hypothesis is strengthened.

Figure 1 about here please

\section{Web.1.0 or Web.2.0 communication strategies}

The transition from the informational web to the conversational web, characterised by the web.1.0 and web.2.0 metaphors, is one that has been of interest to many scholars of online campaigning. Comparing all parties standing in 2009 and 2014 in all countries we note that adoption of web.2.0 has increased significantly between the contests (AOP web.1.0: $2009=.346,2014=.356$ Difference $=10$; AOP web.2.0: $2009=.187,2014=.295$, Difference $=108)$. Web.1.0 prevails as the basis for party online communication strategies. However we find parties embracing a broader range of features that offer the potential for interaction between the organisation and visitors to their websites and linked platforms. This is also confirmed with regression analysis (table 1) which explores the potential for country and party level independent variables to influence web.1.0 and web.2.0 adoption. Time difference is statistically significant only for web.2.0 performance. The historical experience of the party in EP elections is not significant; there are no performance differences between well-established and new parties. Similarly, years in existence plays no important role in the adoption of either strategy.

There are significant country-by-country differences in the adoption of web.1.0 and web.2.0 features. France and Germany perform higher for web.1.0 adoption compared to their Polish and UK counterparts. In terms of adopting a web.2.0 strategy, German parties appear to lag behind in comparison to the other sampled countries.

When looking between parties across the four nations we see that left wing parties tend to remain locked in a web.1.0 paradigm of online campaigning to a greater extent. This is consistent with Copsey's (2003) finding that right wing parties were embracing the full potential of online campaigning to a greater degree and that in previous UK based studies the far-right British National Party outstripped all the competition in using web.2.0 features (Lilleker \& Jackson, 2011). We find that although there is no significant effect shown for being a right wing party, the coefficient is positive for both strategies showing greater sophistication. EU positioning, sceptical, neutral or positive, shows no impact on online performance.

As with general average online performance scores, resources seem the key variable that separates parties, with their standing within the national parliament prior to the European Parliamentary Election used as the proxy. Being a minor parliamentary party appears the strongest explanation for the adoption of web.2.0 features. Minor fringe parties (comparison group) are least likely to adopt features from any strategy. However, it is worth noticing that there is no statistically significant difference in web.1.0 performance between major parliamentary and minor fringe parties. This indicates that parties across the spectrum use a 
range of features most closely associated with the web.1.0 era, however the parties with the greatest resources supplement these with greater web.2.0 functionality.

Interestingly, the parties who gained most seats at previous European parliament appear generally to rely on the usage of web.1.0 features. A general conclusion is that, independent of overall age of a party, the experience of standing in multiple elections or ideological stance of the party, the normalisation hypothesis provides the strongest explanation for differences in online campaign sophistication, when considering adopting web 2.0 features.

Table 2 about here please

\section{The web as a campaigning tool}

The trends relating to the use of different campaigning strategies (Information, Engagement, Mobilization and Interactivity), indicates similar patterns as usage of web.1.0 and web.2.0 strategies. Party history, years of existence, position towards EU as well as party ideology plays no significant role, with the exception being that right leaning parties offer slightly more features that are engaging than their left or centrist counterparts. Engaging features are slightly more likely to be adopted by parties with a record of winning seats in EP elections. Interestingly, the Engaging strategy alone did not change much over time (2009 $\mathrm{AOP}=.248,2014 \mathrm{AOP}=.259$ ). Time difference is statistically significant for Information (2009 AOP=.327 2014 AOP=.343), Mobilization (2009 AOP=.274 2014 AOP=.344) and Interactivity (2009 AOP=.249 2014 $\mathrm{AOP}=.326$ ). In general it was the mobilization strategy that was most employed in 2014, replacing information provision from 2009. But, these general patterns have their national deviations. We find UK parties focusing a little less on information provision online and French parties a little more. German parties lag in terms of lowest performance in interacting. All parties are increasingly adopting features associated with the development of the conversational web and have created their own architecture of participation for supporters to join, mostly through the widespread colonisation of social media platforms, in particular Facebook, Twitter and YouTube. As with previous analyses, the most important variable influencing online performance is resources. We find minor fringe parties performing worse on any online strategy employed, therefore suggesting they struggle to match larger parties and are unable to utilise the potential technology offers to allow them to reach a wider audience online.

Table 3 about here please

Reassessing these findings focusing purely on party type separated by election and nation we find a further mixed picture. Information provision (Table 4) was the most important strategy in 2009 in France, Germany and Poland; however it remained the priority in 2014 in France only. German parties changed their strategy towards mobilization and Polish parties towards interactive communication. In Great Britain the priority shifted from a Mobilization strategy in 2009 to Interactivity in 2014.

Confirming normalization, major or minor parliamentary parties construct the best online communication regardless of strategy or country. The exception is 2009 when the level of adoption of Mobilization, Engagement and Interactivity strategies by Major fringe parties in Great Britain was equal or better than their counterparts. Perhaps this finding relates to the increased focus on online campaigning by UKIP alone. The increase in UKIP's online campaigning activity compared to previous elections (Lilleker \& Jackson, $2010 ; 2011$ ) and embrace of the conversational web indicates an attempt to build support and, once earned, harness their supporters to the campaign. Perhaps this activity is related to UKIP's success in winning most seats overall within the UK contest in 2014, as well as contributing to their success in two by-elections. 
However the interesting finding is not only the average performance in itself, which increased significantly for parliamentary parties, but also improvements in performance over time. Within the countries we find a few interesting tendencies, both progressive and regressive, in changes in online performance (Table 3, 4, 5 and 6, YOY=Year on Year difference). In Poland all parties improved their performance from 2009 regardless of strategy or party size, and interestingly the greatest difference is for minor parliamentary parties. A similar pattern can be found in France, performance improves for all parties, but major fringe parties improved most. Germany and Great Britain offer a more mixed picture, information provision is definitely lower in 2014 than in 2009 regardless of party size. The use of features permitting Mobilization and Interactivity increased slightly in Germany with major fringe parties most improved. There is no visible pattern in Great Britain, performance differs according to party size and year; however one consistent finding is that major parliamentary parties innovated most compared to the other countries' parties. Therefore, while normalisation remains the dominant explanatory hypothesis, there is evidence of ebb and flow in innovations between parties of different types and with differing resource capabilities in some nations.

Tables 4, 5, 6 and 7 about here please

\section{Vote Share}

Determining the impact of online campaigning is very difficult. It is impossible to isolate the online dimension from all other activities. Since we are not able to control for the offline campaign or other independent variable effects, we propose to compare only the potential effect from the adoption of web.1.0 and web.2.0 features, ceteris paribus. Studies have found a positive correlation between being online and a candidates' score in a national election (Koc-Michalska et al, 2014). We suggest that this is an artefact of visibility. That being online leads to greater awareness, possibly as one element of a highly proactive campaign, and so support at the ballot box. Here we suggest that if being online creates visibility we will find no effect from either strategy, however if we find a relationship between one or another strategy we can suggest that the style of campaign may be influential on support. When looking at relationships between a number of variables and vote share overall we see some interesting patterns ${ }^{6}$ (Table 8). However, we focus here on three variables and the interaction between them: national vote share (which allows controlling for party size, possible resources (financial and human) that a party may deploy in campaigning and potential for traditional media coverage); AOP score for the use of web.1.0 and web.2.0 features, and an addition variable, titled interaction (national vote share multiplied by web.1.0 or web.2.0 performance) is constructed. The analysis therefore allows us to control for normalization, the party size effect on online performance and so for the levels of support larger parties receive.

Table 8 about here please

Firstly we find, as expected that the national vote share has a significant effect on EP election score, the largest parties on the whole gain more votes. Secondly, and more surprisingly, we find that a greater commitment to web.2.0 features appears to have a positive effect on vote share; using web1.0 features has no statistically significant effect. Finally, we find the effect of the interaction of national vote and a web.2.0 strategy also offers significant explanation of vote share (interaction with web.1.0 is not significant). The direction of influence is negative, which suggests that the employment of the web.2.0 strategy by a large

\footnotetext{
${ }^{6}$ Due to the bias of omitting variables from analysis we do not concentrate on general findings but on the difference of web.1.0 and web.2.0 effects, however the results confirm, as expected from what is usually a mid-term and second order election there is a penalty in votes for being in government. Also, given the context of this contest, one that was evidenced to a much greater extent elsewhere in the EU, there was an increased vote share for right wing parties with parties neutral on the subject of EU membership being punished.
} 
party is less influential on vote share obtained in second order elections (Figure 2). Rather it is the medium and smaller parties that may gain most from the adoption of a web.2.0 campaign. This finding is consistent with conclusions from simple AOP analysis indicating that the strategies dedicated to direct discussion and responsiveness towards citizens and voters when employed more intensively by middle size parties appear to have a significant influence on electoral results.

Figure 2 about here please

\section{Conclusions}

The study of online campaigning has a long history with most studies finding low innovation in functionality combined with mixed findings relating to the adoption of the latest features, tools and platforms. The sense is that digital technologies are largely moulded to the will of political campaign strategists and, despite suggestions of the social web leading to a new and more social communication paradigm to pervade all spheres of life, interactivity is the preserve of a minority of parties and often an experiment quickly discontinued. Experimentation seemed to be practiced in 2009, particularly studies found that the larger British parties peaked in their use of interactive features for the 2009 EP election, with a more mixed picture visible for the subsequent general election in 2010 and then largely convergence around the use of a range of features in 2014 (Lilleker et al, 2015). With our wider sample of parties some of these smaller differences are masked, permitting our data to show the power of the normalisation hypothesis.

Taking a normative stance, we can confidently claim that parties do not use the full potential that the architecture of the web is offering. On general the AOP scores of the parties is rather low with on average around thirty percent of the potential functionalities available actually featuring. The usage of features from the coding is spread among parties (so each feature is used) however there is no single party using all or even a majority of features available to them (the best AOP score, by the German Pirate Party is 65\%). After more than two decades of development in online campaigning, there remains much potential for innovation. We would suggest, therefore, that features are used due to their perceived utility for meeting campaigning objectives, as would be expected. However this stifles innovation and the shift towards a more interactive paradigm of campaign communication that may positive impact on the engagement of citizens in party politics or broader tendencies towards participation in politics. The suggestion here is that engagement online may lead to engagement offline so being able to interact with a party online might increasing the propensity to be involved in partisan activities offline, such as joining, donating, contacting representatives or even attending party meetings or events.

The dominance of resources in explaining the adoption of a range of features, so making for a more sophisticated online campaign, means that the findings of the many previous studies testing normalization are borne out again in 2014. However, while normalisation is the most powerful explanatory variable, we also find some evidence of ebb and flow in terms of pursuing some strategies; for example in finding that minor Polish parliamentary parties or German fringe parties innovated most in prioritising certain feature functionalities over others when designing their websites. These innovations, however, are likely to be undertaken in the pursuit of votes. Yet, overall, it would appear that rich parties get richer in terms of having more sophisticated online presences and, on the whole, the richer parties with a history of high levels of support still receive the higher levels of votes in EP contests.

However, this simple linear pattern may not be the full story. While analysis of the party campaigns produced few unexpected or interesting findings, it appears when we explore whether there are any explanations for variance in vote share, when controlling for the dividend for being a large party there is a visible web.2.0 effect. We find that parties that offer a more interactive style of campaigning, facilitated 
through placing features that facilitate engagement and interaction, may earn a vote dividend. However, and so in some ways countering the notion that normalization dominates all aspects of campaigning, smaller parties are likely to gain most from this dividend for pursuing a web.2.0 campaign strategy. This finding is important as the data suggests that smaller parties, when adopting more innovative communication strategies, and allowing their supporters to interact with the party and one another, they might become more visible, earn interest, engagement and support. Therefore while we can argue that normalization remains a key explanatory concept, and in terms of both campaign sophistication and vote share the rich parties do get richer, the smaller parties may be able to find an electoral edge if they are willing to release control and offer a more engaging and interactive experience to visitors to their websites. The challenge smaller parties face is how to be ahead of the curve in the ebb and flow of innovations. Across the contests we see an equalising trend in innovation, therefore smaller parties need to retain and grow support while maintaining their accessible and interactive communication style. Therefore, while we may be a little closer to identifying a vote dividend from embracing web.2.0 and going interactive for a niche or fringe party seeking to punch above its electoral weight the advantage earned may be contest specific and a product of the novelty of the party and their communication style rather than long-term partisan attachment hence the positive impact may be fleeting, though detectable when research campaigning effects. 


\section{Bibliography}

Bellamy, C., \& Raab, C. D. (1999). Wiring-up the deck-chairs?. Parliamentary Affairs, 52(3), 518-534.

Bimber, B. (1998). The Internet and Political Transformation: Populism, Community, and Accelerated Pluralism. Polity, 31(1), 133-160.

Chen, P. (2010). Adoption and use of digital media in election campaigns: Austria. Canada, New Zealand. Public Communication Review, 1, 3-26.

Copsey, N. (2003), "Extremism on the net: the extreme right and the value of the Internet", in Gibson, R., Nixon, P. and Ward, S. (Eds), Political Parties and the Internet: Net Gain?, Routledge, London, pp. 218233.

D'alessio, D. (1997). Use of the World Wide Web in the 1996 US election. Electoral Studies, 16(4), 489500 .

Davis, R. (1999) The Web of Politics: the Internet's Impact on the American Political System. Oxford: Oxford University Press.

De Landtsheer C, Krasnoboka N and Neuner C (2005) Participation friendliness of political websites in Eastern and Western Europe. In: Farnen RF, Dekker H, De Landtsheer C, Sünker H and German DB (eds) Democratization, Europeanization and Globalization Trends. Berlin: Peter Lang.

Farmer R and Fender R (2005) E-parties: Democratic and Republican state parties in 2000. Party Politics 11(1): 47-58.

Gandy, O., Toth, E., \& Heath, R. (1992). Public relations and public policy: The structuration of dominance in the information age. Mahwah, NJ: Lawrence Erlbaum

Garzia, D. Trechsel, A.H.; De Sio, L.; \& De Angelis, A. (2015). euandi. Project description and datasets documentation. EUI Working Paper RSCAS 2015/01.

Gibson, R. K., \& Römmele, A. (2009). Measuring the professionalization of political campaigning. Party Politics, 15(3), 265-293.

Gibson RK and Ward S (1999) Party democracy on-line: UK parties and new ICTs. Information Communication and Society 2(3): 340-367.

Gibson R and Ward S (2000) A proposed methodology for measuring the function and effectiveness of political web-sites. Social Science Computer Review 18(3): 301-319.

Hindman, M. (2008). The myth of digital democracy. Princeton: Princeton University Press.

Jackson N (2006) Banking online: The use of the Internet by political parties to build relationships with voters. In: Lilleker D, Jackson N and Scullion R (eds) The Marketing of British Politics: Political Marketing at the 2005 General Election. Manchester: Manchester University Press, 157-183.

Jackson N and Lilleker D (2009) Building an architecture of participation? Political parties and Web 2.0 in Britain. Journal of Information Technology and Politics 6(3/4): 232-250. 
Koc-Michalska, K., Gibson, R., \& Vedel, T. (2014). Online Campaigning in France, 2007-2012: Political Actors and Citizens in the Aftermath of the Web. 2.0 Evolution. Journal of Information Technology \& Politics, 11(2), 220-244.

Koc-Michalska, K., and Lilleker, D. G. (2014) Evolving In Step or Poles Apart? Online Audiences and Networking During Poland and France 2011-12 Election Campaign, International Journal of E-Politics, $5(1), 41-60$,

Koc-Michalska, K., Lilleker, D. G., Surowiec, P., \& Baranowski, P. (2014). Poland's 2011 online election campaign: new tools, new professionalism, new ways to win votes. Journal of Information Technology \& Politics, 11(2), 186-205.

Lilleker, D. G., \& Malagón, C. (2010). Levels of interactivity in the 2007 French Presidential candidates' Websites. European Journal of Communication, 25(1), 25-42.

Lilleker, D. G., Koc-Michalska, K., Schweitzer, E. J., Jacunski, M., Jackson, N. and Vedel, T. (2011). Informing, Engaging, Mobilising or Interacting: Searching for a European Model of Web Campaigning. European Journal of Communication, 26(3), 195-213.

Lilleker, D. G., \& Koc-Michalska, K. (2013). Online political communication strategies: MEPs, erepresentation, and self-representation. Journal of Information Technology \& Politics, 10(2), 190-207.

Lilleker, D. G., Tenscher, J., \& Štětka, V. (2015). Towards hypermedia campaigning? Perceptions of new media's importance for campaigning by party strategists in comparative perspective. Information, Communication \& Society, 18(7), 747-765.

Lilleker, D. G., Koc-Michalska, K., \& Jackson, N. (2015). Social media in the UK election campaigns 2008-14: experimentation, innovation and convergence. In A. Bruns and E. Skogerbo (Eds.) Routledge Companion to Social Media and Politics, London: Routledge.

Margolis M and Resnick D (2000) Politics as Usual: The Cyberspace Revolution. Thousand Oaks, CA: Sage.

Rheingold H (1993) The Virtual Community: Homesteading on the Electronic Frontier. New York: Harper.

Schweitzer EJ (2008) Innovation or normalisation in E-campaigning? A longitudinal content and structural analysis of German party websites in the 2002 and 2005 national elections. European Journal of Communication 23(4): 449-470.

Schweitzer EJ (2009) Europeanisation on the Internet? The role of German party websites in the 2004 European parliamentary elections. Observatorio 3(3): 20-40.

Simmons, G., Thomas, B., \& Truong, Y. (2010). Managing i-branding to create brand equity. European Journal of Marketing, 44(9/10), 1260-1285.

Stempel GH III (2003) Content analysis. In: Stempel GH III, Weaver DH and Wilhoit GC (eds) Mass Communication Research and Theory. Boston, MA: Allyn and Bacon, 209-219.).

Stromer-Galley, J. (2014). Presidential campaigning in the Internet age. Oxford: Oxford University Press . Tenscher, J., \& Mykkänen, J. (2014). Two Levels of Campaigning: An Empirical Test of the Party-Centred Theory of Professionalisation. Political Studies, 62(S1), 20-41. 
Vedel T and Koc-Michalska K (2009) The Internet and French political communication in the aftermath of the 2007 presidential election. Paper presented at the 5th ECPR General Conference, Potsdam.

Watt J. H. and Van den Berg S (1995) Research Methods for Communication Science. Boston, MA: Allyn and Bacon. 
Table 1: Sample size and key national statistics aiding comparison 2009 and 2014

\begin{tabular}{|c|c|c|c|c|c|c|c|c|}
\hline & \multicolumn{2}{|c|}{ GB } & \multicolumn{2}{|c|}{ FR } & \multicolumn{2}{|c|}{ GER } & \multicolumn{2}{|c|}{ PL } \\
\hline & 2009 & 2014 & 2009 & 2014 & 2009 & 2014 & 2009 & 2014 \\
\hline Years in the EU & 36 & 41 & 52 & 57 & 52 & 57 & 5 & 10 \\
\hline Number of seats in EP & 72 & 72 & 72 & 72 & 99 & 96 & 50 & 51 \\
\hline Turnout in 2004 (in \%) & \multicolumn{2}{|c|}{38.9} & \multicolumn{2}{|c|}{42.7} & \multicolumn{2}{|c|}{43} & \multicolumn{2}{|c|}{20.4} \\
\hline Turnout in 2009 (in \%) & \multicolumn{2}{|c|}{34.7} & \multicolumn{2}{|c|}{40.6} & \multicolumn{2}{|c|}{43.3} & \multicolumn{2}{|c|}{24.5} \\
\hline Turnout in 2014 (in \%) & \multicolumn{2}{|c|}{35.4} & \multicolumn{2}{|c|}{42.4} & \multicolumn{2}{|c|}{48.1} & \multicolumn{2}{|c|}{23.8} \\
\hline Number of country's residents (in millions) & 59.8 & 64.3 & 62.1 & 65.8 & 81 & 82 & 37.8 & 38.4 \\
\hline Country's GDP & 116.2 & 106 & 107.9 & 108 & 115.6 & 124 & 56.4 & 68 \\
\hline Internet connections (in $\%$ of population) & 77.9 & 89 & 69.3 & 84 & 67 & 85 & 53 & 65 \\
\hline Number of parties included & 22 & 49 & 31 & 40 & 32 & 28 & 12 & 14 \\
\hline
\end{tabular}

Sources: www.elections2014.eu, www.internetworldstats.com, ec.europa.eu/ 
Table 2: Regression analysis, adoption of web.1.0 and web.2.0 features

$\begin{array}{lll}\text { web.1.0 } & \text { web.2.0 } \\ & \mathrm{N}=228 & \\ \text { B Coef } & & \text { B Coef }\end{array}$

Parties present in both elections '09/' 14

$\begin{array}{cc}.009 & .007 \\ .023 & .104 * * * \\ & \\ -.049^{* *} & .066^{* *} \\ .045^{* *} & .060^{* *} \\ -.067 * * & .063 *\end{array}$

Time difference (2014)

$-.067 * *$

.000

Party years of existence

.000

Party id (comp. single issue party)

Right

$.039 \quad .000$

Left

$.061 * *$

$-.016$

Centre

.049

EU positioning (comp. Positive)

Neutral

.006

$-.028$

Sceptics

.005

$-.016$

Party size (comp. minor fringe)

Major parliamentary

$.087 \quad .134^{*}$

Minor parliamentary

$.117 * * *$

$.186^{* * *}$

Major fringe

$.077^{* *} \quad .105^{* *}$

$\mathrm{NB}$ of seats in EP in previous term

$.005 * \quad .002$

constant

$.259 * * * \quad .112 * *$

$\mathrm{R}^{2}$

.372

.364

Adj $R^{2}$

.328

.319

Sign values: $* * *<.001, * *<.05, *<.10$

OLS regression. Dependent variables: Continues. Panel is based on the parties present online in both EP elections 2009 and 2014. Independent variables: Please see explanation in the text. 
Table 3. Regression analysis, usage of the Internet as a campaigning tool

\section{Information \\ Provision}

Time difference (2014)

Country (comparison Germany)

GB

FR

PL

Party characteristics

Party years of existence

Party id (com. single issue party)

Right

Left

Centre

EU positioning (comp. Positive)

Neutral

Sceptics

Party size (comp. minor fringe)

Major parliamentary

Minor parliamentary

Major fringe

$\mathrm{NB}$ of seats in EP in previous term

constant

$\mathrm{R}^{2}$

$\operatorname{Adj} R^{2}$
B Coef.

.012

$.028^{*}$

\section{Engagement}

$$
\mathrm{N}=228
$$

B Coef.

B Coef.

B Coef.

\section{$-.050 * *$}

$.054 * *$

$-.039$

.000

.022

.037

.023

.020

$-.002$

.075

$.144 * * *$

$.093 * *$

.004

$.244 * * *$

0.355

0.309

.010

.019

$-.003$

$.118 * * *$

.007

.000

.045*

.033

.044

.000

.015

$-.029$

.003

$-.036$

$-.026$
Sign values: $* * *<.001, * *<.05, *<.10$

OLS regression. Dependent variables: Continues. Panel data is omitted due to space limit results are discussed in the text. Independent variables: Please see explanation in the text. 
Table 4. AOP Information provision scores per Year, Party size and Country. Pooled and panel parties.

\begin{tabular}{|c|c|c|c|c|c|c|c|c|c|c|c|c|}
\hline \multirow[b]{2}{*}{$\mathrm{N}=228$} & \multicolumn{3}{|c|}{ GB } & \multicolumn{3}{|c|}{ FR } & \multicolumn{3}{|c|}{$\mathrm{DE}$} & \multicolumn{3}{|c|}{ PL } \\
\hline & ‘09 & '14 & YOY & ‘09 & '14 & YOY & ‘09 & ‘14 & YOY & ‘09 & '14 & YOY \\
\hline general & .293 & .284 & -.009 & .341 & .422 & .081 & .360 & .325 & -.035 & .269 & .360 & .091 \\
\hline major parliament & .318 & .227 & -.091 & .455 & .591 & .136 & .614 & .523 & -.091 & .432 & .545 & .113 \\
\hline minor parliament & .439 & .331 & -.108 & .443 & .565 & .122 & .580 & .561 & -.019 & .250 & .500 & .250 \\
\hline major fringe & .409 & .273 & -.136 & .318 & .614 & .296 & .409 & .400 & -.009 & - & - & \\
\hline minor fringe & .234 & .279 & .045 & .316 & .362 & .046 & .294 & .238 & -.056 & .237 & .273 & .036 \\
\hline
\end{tabular}

Two-way in between ANOVA, statistically significant difference p<.05 for: GB (party size Eta =.143), FR (time Eta = .127; party size Eta = .249), DE (party size Eta = $.575)$, PL(time Eta $=.272$; party size Eta $=.493)$ yoy $=$ change between years $(2014-2009)$.

Table 5: AOP Engagement provision scores per Year, Party size and Country. Pooled and panel parties.

\begin{tabular}{|c|c|c|c|c|c|c|c|c|c|c|c|c|}
\hline \multirow[b]{2}{*}{$\mathrm{N}=228$} & \multicolumn{3}{|c|}{ GB } & \multicolumn{3}{|c|}{ FR } & \multicolumn{3}{|c|}{$\mathrm{DE}$} & \multicolumn{3}{|c|}{ PL } \\
\hline & ‘09 & '14 & YOY & '09 & '14 & YOY & ‘09 & '14 & YOY & ‘09 & ‘'14 & YOY \\
\hline general & .227 & .203 & -.024 & .288 & .357 & .069 & .237 & .198 & -.039 & .217 & .294 & .077 \\
\hline major parliament & .324 & .353 & .029 & .471 & .618 & .147 & .441 & .441 & 0 & .382 & .471 & .089 \\
\hline minor parliament & .333 & .303 & -.030 & .544 & .529 & -.015 & .471 & .373 & -.098 & .235 & .392 & .157 \\
\hline major fringe & .333 & .324 & -.009 & .176 & .412 & .236 & .255 & .318 & .063 & - & - & \\
\hline minor fringe & .168 & .170 & .002 & .241 & .294 & .053 & .176 & .104 & .072 & .176 & .222 & .046 \\
\hline
\end{tabular}

Two-way in between ANOVA, statistically significant difference p<.05 for: GB (party size Eta $=.338$ ), FR (time Eta $=.590$; party size Eta $=.399$ ), DE (party size Eta $=$ $.539)$, PL (time Eta $=.202$; party size Eta $=.562$ ).

Table 6: AOP Mobilization provision scores per Year, Party size and Country. Pooled and panel parties.

\begin{tabular}{lcccccccccccc} 
& \multicolumn{3}{c}{ GB } & \multicolumn{3}{c}{ FR } & \multicolumn{3}{c}{ DE } & \multicolumn{3}{c}{ PL } \\
$\mathrm{N}=228$ & ${ }^{\prime} 09$ & ${ }^{\prime} 14$ & YOY & \multicolumn{1}{c}{09} & ${ }^{\prime} 14$ & YOY & '09 & '14 & YOY & '09 & '14 & YOY \\
\hline general & .300 & .318 & .018 & .281 & .388 & .107 & .271 & .345 & .074 & .221 & .305 & .084 \\
\hline major parliament & .400 & .467 & .067 & .467 & .633 & .166 & .533 & .633 & .100 & .367 & .467 & .100 \\
minor parliament & .333 & .381 & .048 & .433 & .571 & .138 & .517 & .578 & .061 & .233 & .356 & .123 \\
major fringe & .467 & .433 & -.034 & .089 & .467 & .378 & .311 & .493 & .182 & - & - & \\
minor fringe & .243 & .293 & .050 & .264 & .322 & .058 & .200 & .227 & .027 & .185 & .252 & .067 \\
\hline
\end{tabular}

Two-way in between ANOVA, statistically significant difference p $<.05$ for: GB (party size Eta $=.127$ ), FR (time Eta =.146; party size Eta $=.292$ ), DE (party size Eta $=$ .498).

Table 7: AOP Interactivity provision scores per Year, Party size and Country. Pooled and panel parties.

\begin{tabular}{lcccccccccccc} 
& \multicolumn{3}{c}{ GB } & \multicolumn{3}{c}{ FR } & \multicolumn{3}{c}{ DE } & \multicolumn{3}{c}{ PL } \\
$\mathrm{N}=228$ & ${ }^{\prime} 09$ & ${ }^{\prime} 14$ & YOY & ${ }^{\prime} 09$ & ${ }^{\prime} 14$ & YOY & ${ }^{\prime} 09$ & ${ }^{\prime} 14$ & YOY & '09 & '14 & YOY \\
\hline general & .261 & .327 & .066 & .256 & .335 & .079 & .231 & .267 & .036 & .261 & .409 & .148 \\
\hline major parliament & .367 & .500 & .133 & .500 & .433 & -.067 & .433 & .500 & .067 & .367 & .533 & .166 \\
minor parliament & .311 & .438 & .127 & .383 & .467 & .084 & .433 & .467 & .034 & .233 & .444 & .211 \\
major fringe & .400 & .400 & 0 & .133 & .367 & .234 & .244 & .427 & .183 & & \\
minor fringe & .205 & .295 & .090 & .227 & .294 & .067 & .177 & .157 & -.020 & .244 & .370 & .126 \\
\hline
\end{tabular}

Two-way in between ANOVA, statistically significant difference p<.05 for: GB (party size Eta =.163), FR (party size Eta = .297), DE (party size Eta $=.470$ ), PL (time Eta $=.290)$ 
Table 5: Poisson regression, vote share controlling for party size

\begin{tabular}{|c|c|c|}
\hline & \multicolumn{2}{|c|}{ Vote share in EP elections } \\
\hline & \multicolumn{2}{|c|}{$\mathrm{N}=228$} \\
\hline & Coef. & Std. Err. \\
\hline \multicolumn{3}{|l|}{ Party characteristics } \\
\hline Party years of existence & -.001 & $(.001)$ \\
\hline \multicolumn{3}{|l|}{ Party id (comp. Left) } \\
\hline Right & $.299 * *$ & $(.139)$ \\
\hline Centre & .201 & $(.159)$ \\
\hline Single issue/other & $-1.961 * * *$ & $(.264)$ \\
\hline \multicolumn{3}{|l|}{ EU positioning (comp. Positive) } \\
\hline Neutral & $-.959 * *$ & $(.299)$ \\
\hline Negative & -.066 & $(.241)$ \\
\hline Stood in previous EP election & $.693 * *$ & $(.274)$ \\
\hline Vote share in last national election & $.096 * * *$ & $(.017)$ \\
\hline In government & $-.329 * *$ & $(.106)$ \\
\hline web.1.0. performance & 1.484 & $(.937)$ \\
\hline web.2.0. performance & $2.244 * * *$ & $(.586)$ \\
\hline Interaction (National vote share $*$ web.1.0.) & -.037 & $(.037)$ \\
\hline Interaction (National vote share $*$ web.2.0.) & $-.054 * *$ & $(.021)$ \\
\hline Constant & -.831 & $(.513)$ \\
\hline Pseudo $\mathrm{R}^{2}$ & .651 & \\
\hline
\end{tabular}

Poisson regression. Dependent variable: Vote share (\%) in 2009 and in 2014 election. 


\section{Appendix}

Table A1. Indexes of the online features

web.1.0: Update on the website in last 2 weeks; Any form of newsletter communication; Special section: media; Videos online; Special section: radio; Special section: info from press conferences; Calendar of events; FAQ section; Animated photo on the website; Search engine; Easy contact; Political games; Online polls; Version for disabled visitors (font size); Version for disabled visitors (reading); Promotional materials to download; Possibility to download content; Party history and achievements; Party code of conduct; Possibility to become a volunteer; Possibility to donate money; Possibility to become a member of party; Information about political program; Website registration for members only; Online shop; Website available in many languages; Translation to other languages; Information about national political issues; Information about EU political issues; Information about voting procedure

web.2.0: Possibility to comment on news; Blog; Agenda can be updated by visitors; A channel on video sharing websites; Possibility to comment (a video sharing website); Possibility to rate videos; Life webcam; Online photo gallery; Possibility to comment (online photo gallery); Possibility to rate (online photo gallery); Profile on SNS; Online forum or chat (among visitors); Online forum or chat (with politicians); RSS subscription; Possibility to share content of the website; Possibility to share content on social media; Tag Cloud on the website; Information about political program (interactive format)

Information provision: Update on the website in last 2 weeks; Blog; Any form of newsletter communication; Special section: media; Videos online; Special section: radio; Special section: info from press conferences; Calendar of events; FAQ section; Search engine; RSS subscription; Tag Cloud on the website; Party achievements in previous terms; Possibility to download content; Party history; Party code of conduct; Information about political program; Website available in many languages

Engagement provision strategy: Blog; Any form of newsletter communication; Videos online; Special section: radio; Special section: info from press conferences; A channel on video sharing websites; Life webcam; Animated photo on the website; Online photo gallery; Political games; Online polls; Possibility to share content of the website; Possibility to share content on social media; Version for disabled visitors (font size); Version for disabled visitors (reading); Tag Cloud on the website; Online shop

Mobilization provision strategy: Possibility to comment on news; Any form of newsletter communication; Calendar of events; Agenda can be updated by visitors; Possibility to rate videos; Possibility to rate (online photo gallery); Online polls; Online forum or chat (among visitors); Possibility to share content of the website; Possibility to share content on social media; Promotional materials to download; Possibility to become a volunteer; Possibility to donate money; Possibility to become a member of party; Information about political program (interactive format)

Interactivity provision strategy: Possibility to comment on news; Agenda can be updated by visitors; A channel on video sharing websites; Possibility to comment (a video sharing website); Life webcam; Online photo gallery; Possibility to comment (online photo gallery); Easy contact; Online polls; Profile on SNS; Online forum or chat (among visitors); Online forum or chat (with politicians); Possibility to share content of the website; Possibility to share content on social media; Information about political program (interactive format)

Figure 1: General online performance (AOP) by nation and party type 


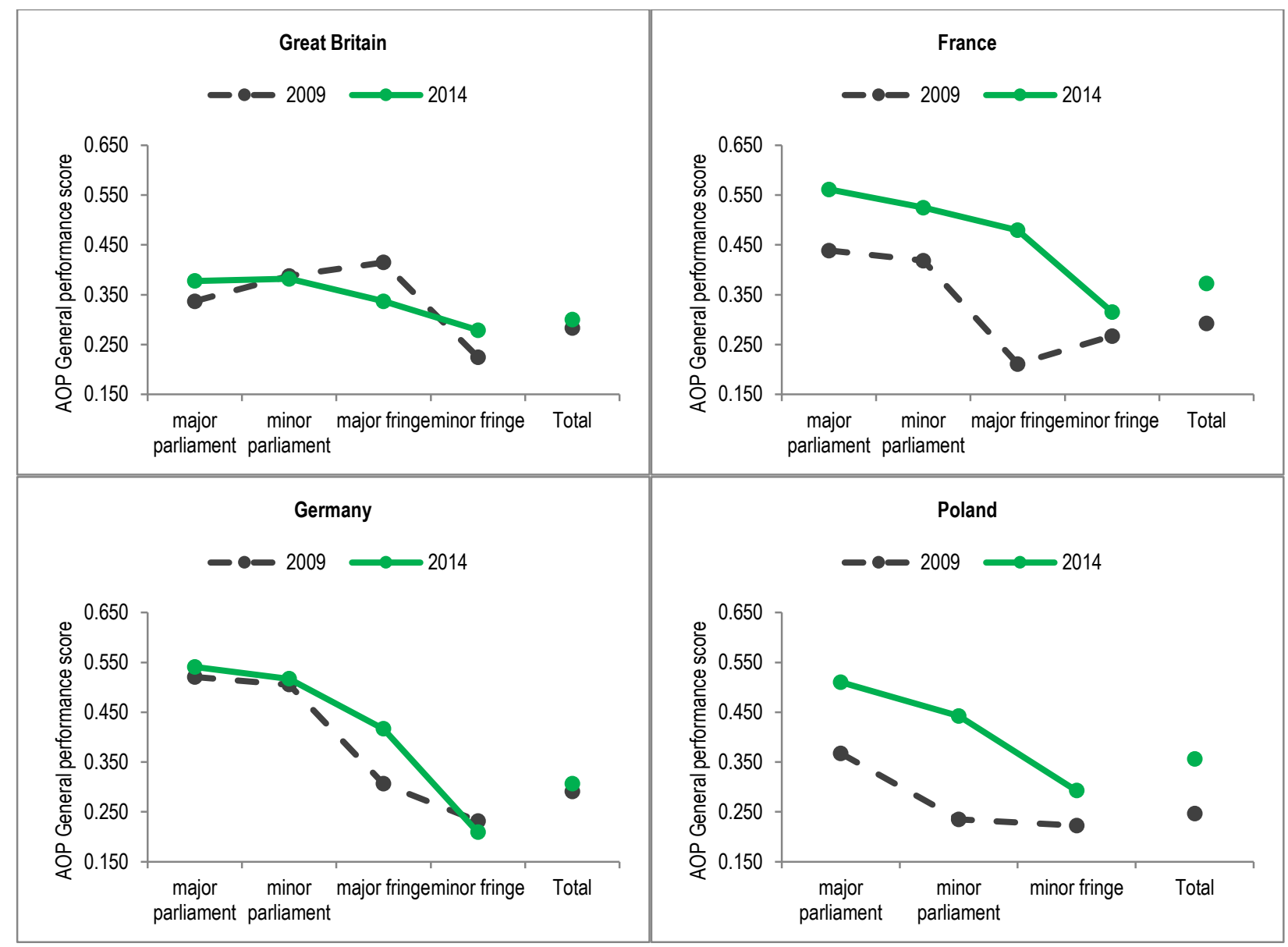

Note: Two-way in between ANOVA, statistically significant difference $\mathrm{p}<.05$ for: GB (party size, Partial Eta Squared $($ Eta) $=.217$ ), FR(time, Eta=.148; party size Eta = .347 ), DE (party size, Eta $=.581$ ), PL (time Eta $=.325$; party size Eta $=.395$ ). 
Figure 2. The relationship between national vote share, web.2.0 and EP vote shareEffects of web.2.0 performance on vote share in EP elections.

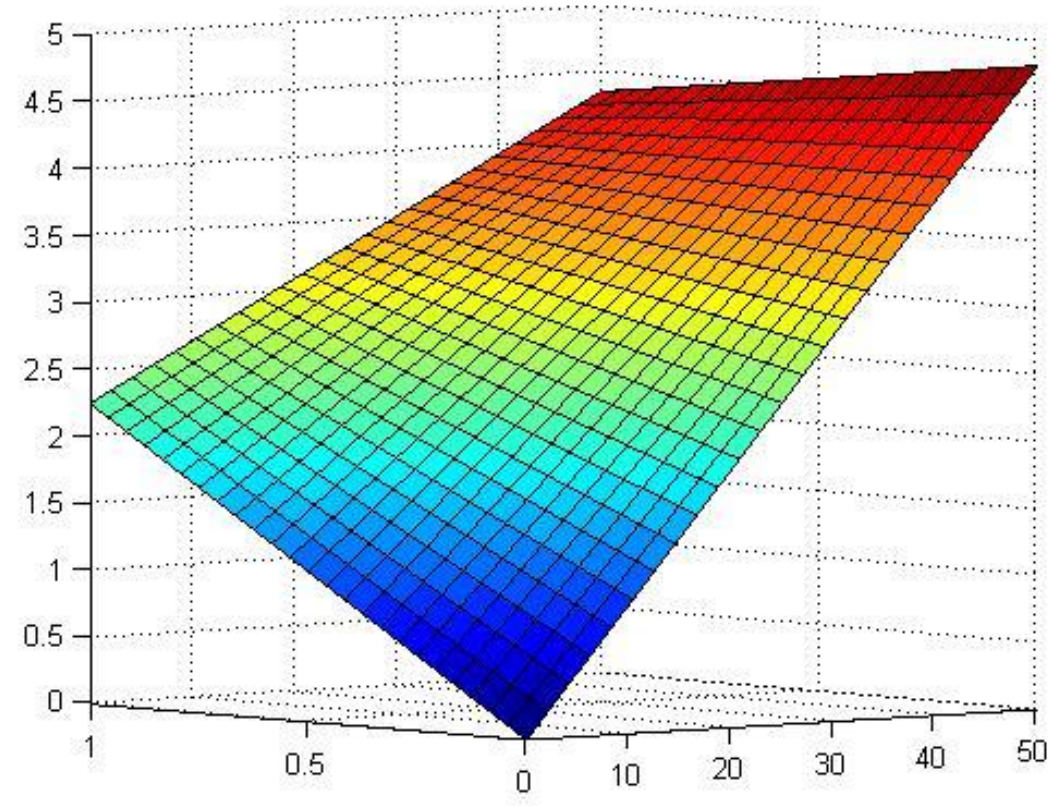

Note: Axe X (0 to 1) web.2.0 performance, Axe Y ( 0 to 50) national vote share, Axe Z (0 to 5) effect on the dependent variable (on top of the average). The figure can be read as follows: There is a direct positive effect on the dependent variable (vote share in EP election) as web 2.0 or the share of the party in the national vote increase (as exhibited by the increases in the border values for the other variable being held at zero). The interaction term between the two variables is, however, negative as shown by the falling dependent variable outcome at high levels of the national vote share with the increase of the web 2.0. This indicates that parties with the largest national score do not gain from using a 2.0 web strategy. 